\title{
Lembranza de Julio
}

Pertenzo á derradeira xeración que tivo que saír de Galicia para estudar Pedagoxía. Así como eu marchaba para Madrid en setembro de 1973, abríase en Compostela a nova Facultade de Filosofía e Ciencias da Educación. Ata aqueles anos so se podía estudar Pedagoxía en catro universidades: Madrid, Barcelona, Valencia e Salamanca pero as cousas estaban cambiando moito coa reforma de Villar Palasí nos estertores do franquismo e unha nova cultura pedagóxica empezaba a asomar no horizonte, moito máis alá do que a Lei Xeral de Educación amosaba.

Eu era un rapaz novo que quería cambiar radicalmente o mundo, e pensaba que a ferramenta máis potente para facelo era a educación, e pasei dunha incipiente inclinación pola filosofía a unha forma práctica de desenvolver as miñas ideas, de entender as arelas das persoas, de acadar un mundo máis luminoso e cheo de sorrisos. Deixei Compostela e fun a Madrid nunha época na que todo estaba fervendo. Era o momento das condenas polo xuízo 1001 a CC.OO. e do fusilamento de Puig Antich pouco despois, e realmente todo se movía naquela universidade, pero o que menos se movía era aquela sección de Pedagoxía á que cheguei e sentinme como un marciano.

Eu aínda non tiña unha conciencia tan desenvolvida, como a tiven poucos anos despois, para entender o que se perdera dende o ámbito educativo coa Guerra Civil. Nacín nunha familia perseguida polo franquismo e que sufriu nos anos máis duros da ditadura, e xa con oito ou nove anos recoñecía unha bandeira republicana, pero na miña casa, naquela época, se falaba entón con moita prudencia do pasado e eu tiña que aprender por fora. En Madrid empecei a vivir cuns amigos (que aínda o son) que estudaban Ciencias Políticas e as nosas conversas xiraban arredor das liortas entre anarquistas e comunistas na Guerra Civil e do que acontecera en Maio de 1968. A nosa casa viña moita xente de tons excedidos, e todos queriamos merendarmos o mundo e pensabamos en acabar co capitalismo, e non nos conformabamos con vivir nunha "democracia burguesa" e víamos a Plataxunta como unha traizón.

Era evidente que eu vivía nunha grande distancia entre os meus amigos libertarios, trotskistas ou maoístas cos que me movía pola cidade e o campus, e o ambiente timorato que tiña na miña clase da Facultade. Coido que a pedagoxía pola que tiña interese estaba noutra parte, non entendía aínda ben onde exactamente, pero non naquel ambiente. É certo que neses anos por clase tiven compañeiros e compañeiras excelentes entre os que non podo deixar de citar a Aída Terrón, Carmen Colmenar, Miguel Escalera ou Pilar López, pero eu buscaba algo máis alá do antifranquismo, quería romper cunha organización do mundo inxusta, non me chegaba con poder berrar nunha gaiola. "O importante é vivir, non dobrarse cun traballo escravo" pensaba eu con vinte un ou vinte dous anos. 


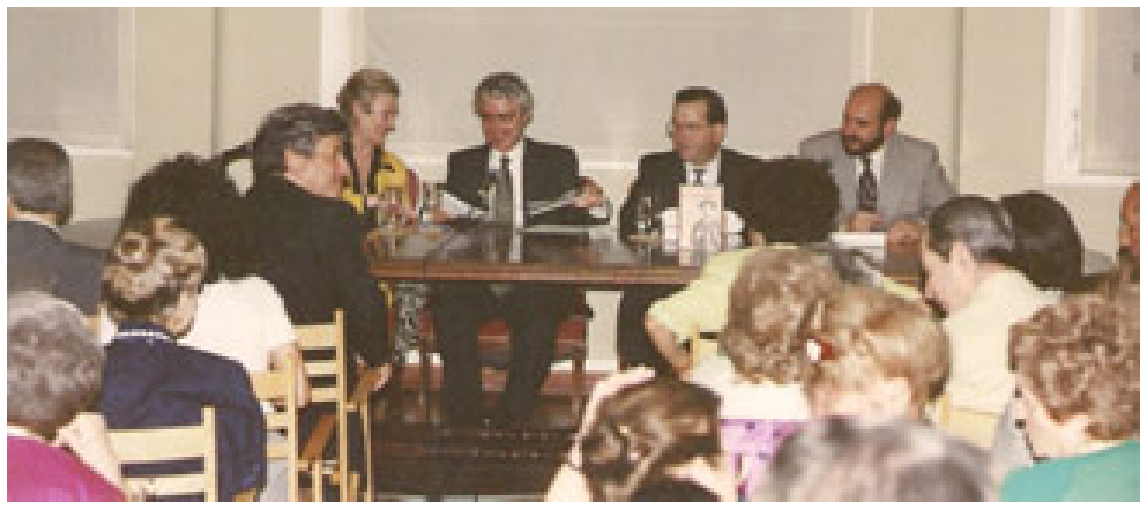

Presentación da biografía de Cossío na Residencia de Estudiantes no ano 1994. Presiden a mesa, ademáis do autor, Natalia Cossío, o ministro de educación Suárez Pertierra e o profesor Julio Ruiz Berrio. En primeira fila pode verse, entre outros, ó director de entonces da Residencia D. José García Velasco.

A primeira vez que escoitei falar de Francisco Giner de los Ríos e do krausismo, foi nas clases de Xosé Fernando Filgueira Valverde no antigo Instituto Masculino de Pontevedra, hoxe Sánchez Cantón. Filgueira utilizábaos para explicarnos a Xeración de 1898, e nalgún momento incluso fíxonos escoitar fragmentos do Arquivo da Palabra. Aos meus dezaseis anos eu pensei que aquilo era bastante escuro e non lle din entón máis importancia. Pero pouco despois lembro que en Pontevedra abrírase unha academia privada que chamaban "Francisco Giner de los Ríos" promovida polos irmáns anarquistas Cuña Casasbellas e varios membros do Partido Comunista (pois si, houbo un tempo en que podían andar xuntos). Lembro como a miña nai acolleu cun sorriso aquel acontecemento. "Volven", dixo polo baixo. Eu entón descoñecía que pertencera na súa xuventude ás JSU, e moito do seu pasado republicano.

Cando comezamos o curso 1975-1976, tiñamos a materia Historia da Educación II, que nos empezou a dar o adxunto á cátedra. Chamábase Julio Ruiz Berrio. Eu non tiña naquel tempo especial afección pola historia da educación, so estaba alí para transformar o mundo aprendendo pedagoxía. Julio era correcto e afable, pero gardaba as distancias cos alumnos tratándonos sempre de "usted" e a miña vestimenta de mozo iracundo non podía ofrecerlle moita confianza. As súas clases eran bastante distintas das outras, non so amenas, senón que nos ían descubrindo retallos dun tempo pasado que descoñecíamos completamente. Lémbrome do dominio que tiña sobre a época de Carlos IV e como fun descubrindo aos ilustrados españois pola súa man, como describía unha sociedade que tan ben retrataba Goya, pero que el ía debullando desde a perspectiva dos contrastes entre aquela España negra e os poucos afrancesados que a denunciaban.

En 1976 celebrábase o centenario da Institución Libre de Enseñanza. Naqueles días empezabamos a recuperar a memoria que quixeron agochar os franquistas, e os meus amigos ácratas, claro está, reivindicaban a Ferrer. Merquei un libro seu que lin de corrido, pero non lle atopei moito gancho, nin graza. E por aquelas semanas Julio empezou a 
explicarnos como foi desenvolvéndose todo aquel movemento krausista. Falábanos da viaxe de Sanz del Río e da cuestión universitaria e deunos algúns textos de Giner, que lin con abraio. Acababa de aparecer Cuadernos de Pedagogía que Miguel Escalera vendíanos a ducia e media de estudantes, e nunha ocasión apareceu co número dedicado a Institución Libre de Enseñanza. Coido que o lin enteiro tres ou catro veces. E ao rematar o curso fun a ver a Julio dicíndolle que ía facer o doutorado e que quería estudar as Misións Pedagóxicas e pregunteille se había algún estudo no que puidera ilustrarme. Díxome que ninguén fixera nada e miroume con esa discreción e distancia calculada coa que ollaba aos estudantes, quizais acostumado a escoitar a moitos cos que finalmente non ocorría nada, e aconselloume dúas cousas: que lera no Instituto San José de Calasanz ás memorias do Padroado, e que fose pola Academia da Historia e buscase alí entre os papeis da Fundación Francisco Giner, que apenas estaban investigados.

Non sabía Julio como estaba determinando o meu futuro. Empecei a primeiros de setembro de 1976 mirando aqueles libros e papeis e aínda sigo con esa teima. Lembro que viñera nunha ocasión a unha festa de estudantes na que eu toquei a gaita exercendo de galego e gustáballe departir as veces no bar con nós, pero non xogaba a facer demagoxia, nin a facerse o simpático, pero cando tiñas ocasión de falar con el no despacho a súa conversación era agradable e chea de suxestións. Sorría cando facías un descubrimento elemental como cando pregunteille asustado que era iso da masonería e porqué Enrique Herrera Oria acusaba aos institucionistas de masóns, ou cando descubrías que algúns dos grandes protagonistas da educación republicana aínda vivían e regresaban do exilio, e eu atopaba o que escribiran cincuenta ou sesenta anos atrás.

Ao rematar a carreira eu tiven que facer o servizo militar na Armada e fixen todo o que puiden para regresar a Madrid, e continuar investigando. Fun destinado ao vello Ministerio de Mariña e con moita frecuencia ía ao San José de Calasanz para seguir lendo aqueles libros e tomar notas. Algún día tenme visto Julio con traxe de mariñeiro, e coido que gustáballe ver o interese que estaba collendo no tema porque descubríalle a el tamén cousas, que seguíamos comentando.

Despois de defender a tesiña en 1979 díxenlle que quería continuar coa figura de Cossío e deume para adiante. Pero poucos meses despois marchei para Lugo, e o que pensaba que ía ser un traballo de tres ou catro anos converteuse en dez. Antes de marchar fun a súa casa na que acostumaba a convidarme a un licor matutino, e entregueille un informe sobre as fontes de documentación que fora descubrindo para a tese "Preocúpate da tese e dos teus alumnos", me dixo ao marchar. A vida foi evolucionando para os dous. Julio gañou a súa praza de catedrático en Oviedo e alí o fun a visitalo en varias ocasións. Cando eu tiña xa lista a tese regresou a Madrid, pero preferiu que a defendera en Oviedo porque os trámites burocráticos eran máis rápidos, pero coido que tamén porque gustáballe volver a unha cidade na que pasou un tempo moi feliz. Lembro que en 1990 foi cando coñecín a Carmen Diego, a Montse, a Violeta, a Ángel e puiden comprender mellor aqueles anos que pasou en Oviedo con Aida como anfitrioa. 


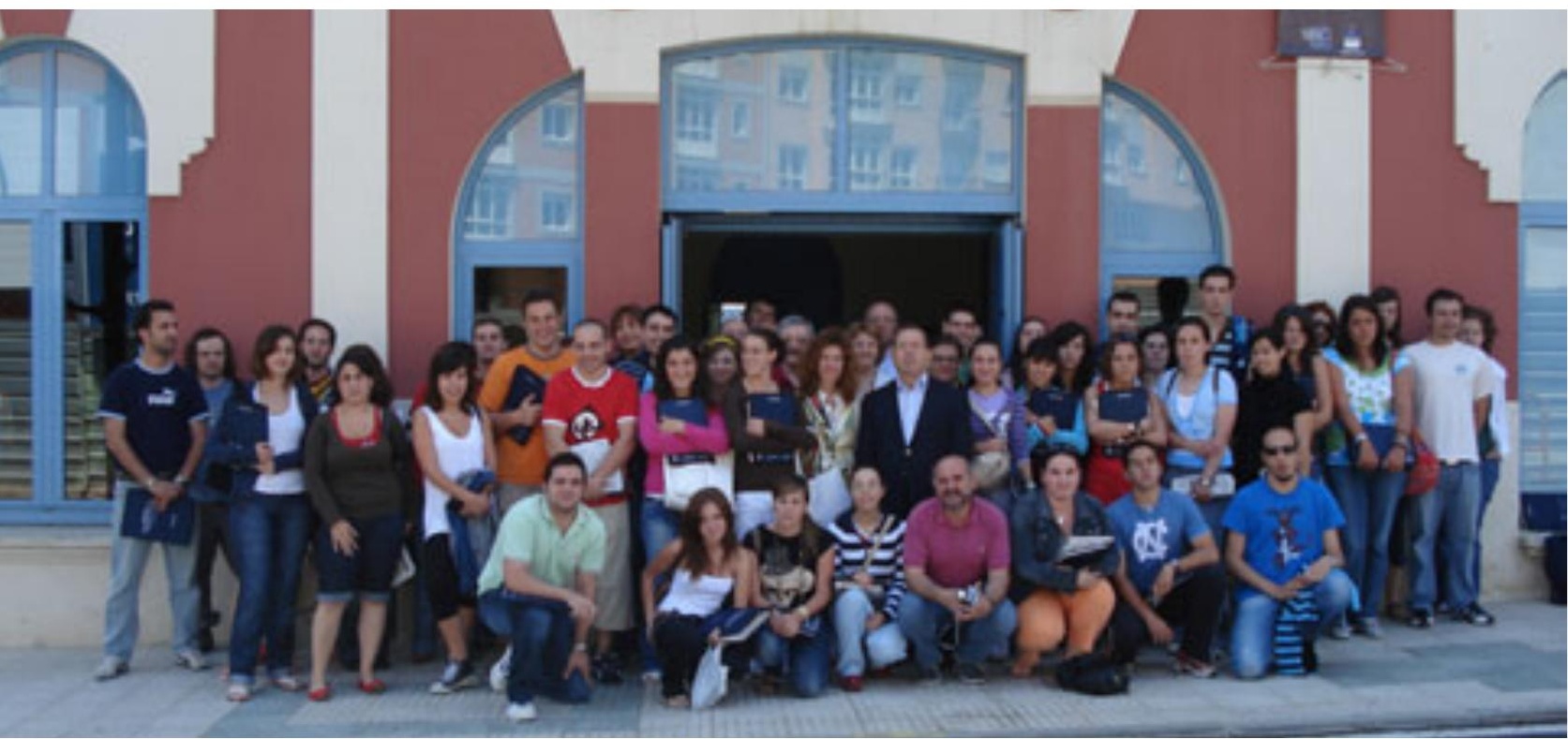

Grupo de alumnos e participantes no curso de vran do 2007 que a USC celebraba tradicionalmente en Foz (Lugo)

Entre 1980 e 1990 foron para min anos de formación como investigador, das miñas primeiras publicacións e presentación en sociedade. Eu viña de Madrid, e realmente empecei a contactar cos meus compañeiros galegos en 1982, en Alcalá de Henares, onde Julio amosouse como o líder indiscutido do noso gremio. Ao contrario de Antón, Vicente ou Herminio eu fora o seu alumno e sentíame sempre noutra dimensión, con máis proximidade intelectual, máis preto. En 1985 invitoume a participar na homenaxe a Cossío e en 1990 fixemos o coloquio de Santiago, onde realmente se fraguou o grupo galego. Foi a partir dese ano cando a miña relación con Julio foi más intensa. Despois de ler a tese fíxome un aparte e díxome, "o teu traballo é moi bó, debes presentalo ao premio nacional de investigación educativa". E cando fun premiado quedamos en Madrid, e díxome "Vas a coñecer a Residencia de Estudiantes que foi novamente aberta, e xa falei con eles e teñen interese en publicar a tese".

Eu fora moitas veces ao Instituto San José de Calasanz pero nunca me achegara ata aqueles edificios de ladrillo, que ninguén me dixera que eran os da Residencia histórica. Lémbrome que un día soleado nos sentamos na entrada do hotel e alí falamos con José García-Velasco quen apareceu co meu libro sobre as Misións Pedagóxicas. En 1994 presentoume o libro biográfico de Cossío en compañía de Natalia, a neta de Cossío e o ministro Gustavo Suárez Pertierra, eu nunca me vira rodeado de tanta xente coñecida: estaba un numeroso grupo de membros da Fundación Francisco Giner, e moitos colegas madrileños. Coido que nunca firmei tantos libros na miña vida. Ao despedirnos ese día díxome: "Y ahora que no se te suba a la cabeza". 
Ese mesmo ano puiden gozar da súa compañía como nunca outra vez tiven ocasión. Fomos a Ámsterdam ao congreso da ISCHE, e nun momento escapamos os dous daquelas reunións nas que só se escoitaba falar en inglés para visitar o RijksMuseum. El tiña moito interese en ver a Ronda de Noite de Rubens, e foi unha das poucas salas que visitamos, e por suposto despois, a toda presa, fomos a ver o Museo Van Gogh, e comemos xuntos nun restaurante italiano. Aprendín ese día que visitar un gran museo pode ser un pracer exquisito dunha hora e catro obras senlleiras, e non acabar saturado e cansado querendo ollalo todo de sala en sala. Xa outro día quedamos con Sjaak e Marimar na Haya para ver a zona do Binnehof e entramos no Mauritshuis. Eu non sabía o que ía ver alí pero Julio si: e de repente apareceuse a Lección de anatomía de Rembrandt, e algún Vermeer, Steen, Holbein, Hals que arrepiaban da emoción, saber que estaban nun museo tan pequeno e visitable.

Durante vinte anos coincidimos moitas veces máis e pasei con el outros momentos entrañables. Tiña moita graza e unha intensa conversación. Non lle gustaba que lle fixeran as beiras, pero el tampouco era moi de facer loanzas. Notábaselle moito que desprezaba aos fonchos e presuntuosos, era serio no traballo e moi rigoroso en todo o que afirmaba, e axudaba moito cando amosábaslle unha preocupación, unha hipótese que podía ser confirmada. Tiña unha especial predilección por contar a historia da formación dos mestres nas súas orixes e a moitos que os formamos coido que nos marcou coa súa maneira de relatar as dificultades que tivo a profesión para abrirse paso e ser recoñecida. Eran as súas publicacións onde podías ler esas inquedanzas pero era nos momentos informais cando sentías a importancia que seguíalle dando ao labor dun mestre primario.

En 2002 puiden organizar a primeiro curso de verano en Foz, e inviteino a vir. Foron dez anos no que estiven atendendo a moitos colegas con temas que eu consideraba pertinentes e actuais, en sete das dez ocasións contei con Julio. Era feliz eses días. En 2003 que falabamos das Misións Pedagóxicas quedouse toda a semana, e ata me pediu un certificado de participación que eu logo esquecinme de mandarlle. Ao acabar as sesións paseabamos todas as tardes ata o final do peirao, e estabamos un rato de conversa ao pe do faro. Cando estaba, ía a todas as conferencias pero non ás da primeira hora da tarde: é que gustáballe ver o final de etapa do Tour, segundo contoume un día confidencialmente.

Como conferenciante gardaba sempre as formas académicas e coido que debía sentirse espido se non levaba chaqueta e garabata. Tolerante e con moito sentido do humor, vital nas súas afirmacións, as veces cunha certa retranca cando o presentabas na periferia peninsular, e rematabas de expoñer os seus méritos engadía cun sorriso aquilo de "e de Madrid". De todas as conferencias que veu dar a Foz aqueles anos sorprendeume especialmente a de 2006 na que falou dos planos de reforma educativa dos ilustrados españois. Eu lle escoitara nunha ocasión falar de que as cidades podían estudarse pola situación na que se atopaban as súas institucións educativas dentro delas, porque ían condicionando moitas veces o seu crecemento. Pero non maxinaba que estaba pensando no Madrid do século XVIII, e sinto que non deixara un texto daquela disertación porque coido que era un modelo que podía aplicarse a outras moitas cidades. 
O primeiro día do Coloquio de Cádiz saín a almorzar cedo ao comedor no Parador onde aloxárame e alí estaba Julio. "¡Qué tal Don Eugenio!" díxome con certa sorna. Pareceume algo ensimesmado e solitario. Queixouse dos colegas que se xubilaban anticipadamente, "é porque non teñen vocación e en realidade nunca gustoulles a ensinanza", remataba. Mirándoo eu pensaba que aquel mestre de todos nós seguía sendo o mestre que non se daba por vencido, e que, de seguro, a súa maior ilusión seguía sendo ter novamente algún discípulo ao que lle puidera transmitir cousas, ao que poder orientar e sentarse nunha mesa como agora estabamos os dous naquela mañá gaditana. Coincidimos as dúas mañás seguintes no mesmo lugar. Na última preguntoume como quedaran as eleccións á xunta directiva da SEDHE, pois el marchara despois de votar. E logo me dixo que ía estar pouco tempo nas sesións porque quería facer algunhas compras antes de coller o tren e regresar a Madrid. Aquela mañá pasou por onde eu estaba, el ía sen compañía e eu con certa présa porque quería entrar a escoitar algunhas intervencións que levaba apuntadas e deixeino pasar, deume certa coraxe non ter parado para botar un conto porque cando saín da sesión xa non estaba.

Unhas semanas máis tarde Antonio Viñao dábanos a aciaga nova do seu pasamento.

Eugenio OTERO URTAZA Universidade de Santiago de Compostela 